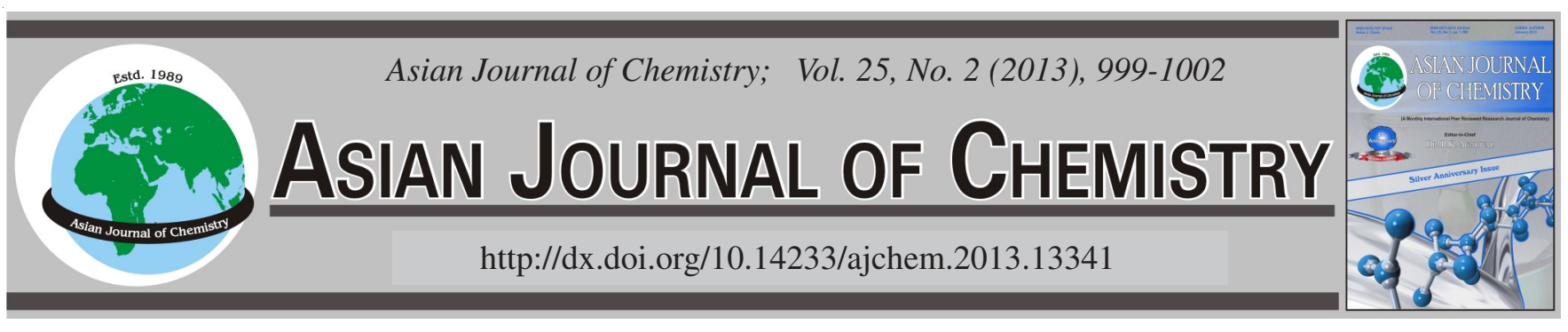

\title{
Spectrophotometric Multicomponent Resolution of a Tablet Formulation Containing Lisinopril and Hydrochlorothiazide by Multivariate Calibration Methods
}

\author{
Sule Dinç*, ÖZlem Aksu Dönmez, Bürge Asçı and AbdürrezZak E. Bozdogan
}

Department of Chemistry, Faculty of Science and Arts, Yildiz Technical University, Davutpasa Campus, 34220 Istanbul, Turkey

*Corresponding author: Fax: +90 212 3834134; Tel: +90 212 3834156; E-mail: sule_dinc@yahoo.com

Partial least squares (PLS), principal components regression (PCR) and multiple linear regression (MLR) methods were used for the determination of lisinopril (LIS) and hydrochlorothiazide in a pharmaceutical formulation. Experimental calibration matrix was constructed using 25 samples, according to multilevel multifactor design. The concentration ranges considered were 4-20 $\mu \mathrm{g} \mathrm{mL}^{-1}$ for lisinopril and 3-11 $\mu \mathrm{g} \mathrm{mL}^{-1}$ for hydrochlorothiazide. The absorbances were recorded between 190 and $400 \mathrm{~nm}$ every $1 \mathrm{~nm}$. The validation of the multivariate methods was realized by analyzing the synthetic mixtures of lisinopril and hydrochlorothiazide. These multivariate methods were also applied to the commercial tablet formulations containing lisinopril and hydrochlorothiazide. High performance liquid chromatography method was used as a comparison method. The results obtained were statistically compared with each other.

Key Words: Lisinopril, Hydrochlorothiazide, Multivariate calibration methods, Simultaneous spectrophotometric determination, Tablet.

ᄂ - - - - - - - - - - - - - - - - - - - - - - - - - - - - - - - - - - - - - - - - - - - - - - - - - - - - - - - - - - - - - - - - - - - -

\section{INTRODUCTION}

The combination of lisinopril and hydrochlorothiazide (Fig. 1) is used to treat high blood pressure. Lisinopril, an angiotensin-converting enzyme (ACE) inhibitor, works by relaxing blood vessels, causing them to widen. Hydrochlorothiazide, a thiazide diuretic, increases the amount of urine, therefore decreasing excess water and salt in body. This medication may also be used to treat congestive heart failure and to help protect the kidneys from damage due to diabetes.

Some analytical techniques have been used for the simultaneous determination of these components such as spectrophotometry $^{1,2}$, HPLC $^{3}$, HPTLC and classical least squares (CLS) and principal component regression (PCR) ${ }^{4}$ and capillary electrophoresis ${ }^{5}$.

In spite of widely use of chromatographic techniques, these methods have the disadvantages requiring expensive equipment and demanding expert operators. UV-VIS spectrophotometry is also used in different fields of chemical analysis on account of its rapidity, simplicity, applicability and low cost. However, as is usual in other spectroscopic techniques, when analyzing mixtures of components that show overlapping spectra, they often cannot be successfully resolved and require resolution by using simple clean-up and seperation procedures. So, developing an alternative analytical techniques are very important for pharmaceutical samples because of demanding simple, cheap and fast analytical methods.<smiles>NCCCC[C@H](N[C@@H](CCc1ccccc1)C(=O)O)C(=O)N1CCC[C@H]1C(=O)O</smiles>

Fig. 1. Chemical structures of lisinopril and hydrochlorothiazide

In recent years, multivariate calibration methods are playing an important role for the multi-component analysis of mixtures. They have the advantage of using full spectra and are useful for the resolution of complex mixtures of analytes. Multivariate calibration allows the rapid and simultaneous determination of each component, with minimum sample preparation, reasonable accuracy and precision and without need of time-consuming separations.

Partial least squares, principal component regression and multiple linear regression are receiving increasing attention as multivariate calibration techniques that have been successfully applied to spectrophotometric analysis of multicomponent drug mixtures ${ }^{6-17}$. Our working group also reported that the simultaneous determination of mixtures of some components in pharmaceutical and food products by partial least square regression using PLS-2 formalism ${ }^{18-20}$. The aim of this study is to show possibility of using PLS-2, PCR and MLR 
and for quantifying these components simultaneously in pharmaceutical preparations. In order to appraise the results obtained by proposed methods, HPLC method was used and the results of these methods were compared.

\section{EXPERIMENTAL}

Lisinopril standard (100.3\% purity) and hydrochlorothiazide standard (101.7\% purity) were kindly supplied from Abdi Ibrahim Pharmaceutical Industry (Istanbul, Turkey). Analytical grade methanol, potassium dihydrogen phosphate and phosphoric acid were purchased from Merck. HPLC grade acetonitrile and Milli-Q water were used. Stock solutions of lisinopril $\left(200 \mu \mathrm{g} \mathrm{mL}^{-1}\right)$ and hydrochlorothiazide $\left(100 \mu \mathrm{g} \mathrm{mL}^{-1}\right)$ were prepared in methanol. Standard solutions and mixtures of drugs were freshly prepared by appropriate dilution of stock solutions with methanol.

The "Zestoretic Fort ${ }^{\circledR ”}$ " commercial tablet samples containing $20 \mathrm{mg}$ of lisinopril and $12.5 \mathrm{mg}$ of hydrochlorothiazide was acquired from Turkey pharmacies.

The absorbance measurements were performed with an Agilent 8453 UV-VIS Spectrophotometer, using $1 \mathrm{~cm}$ quartz cells. All calculations for multivariate calibration methods were performed in Matlab 7 using a software provided by PLSToolbox 5.2. Chromatographic analysis were performed using a Shimadzu HPLC system consisting of a model LC-20AT pump unit, SPD-20A UV-VIS detector, $772520 \mu \mathrm{L}$ sample injection and a computer. The separation was made on a Inertsil ${ }^{\circledR}$ ODS-3 (4.6-250 mm) RP column using acetonitrile and $0.025 \mathrm{M} \mathrm{H}_{3} \mathrm{PO}_{4} / \mathrm{KH}_{2} \mathrm{PO}_{4} \mathrm{pH}: 3$ buffer solution as mobile phase with an elution isocratic system. The detection was made with a variable UV-VIS detector fixed at $213 \mathrm{~nm}$. The flow rate was $1.0 \mathrm{~mL} \mathrm{~min}^{-1}$.

\section{Procedures}

Calibration and validation sets: Mixtures with varying concentrations of lisinopril and hydrochlorothiazide were analyzed by UV-VIS spectrophotometer and calibration and prediction data sets were constructed. A 25 set was built according to multilevel multifactor design ${ }^{21}$ for calibration with PLS-2, PCR and MLR. Multilevel multifactor design is the antithesis of the classical (one-at-a-time) design in which the response is investigated for each factor while all the other factors are hold at a constant level. Therefore, there are three reasons for preferring a factorial design to a classical design. Firstly, while the multilevel multifactor design detects and estimates interactions, the classical design can not. Secondly, if the effects of the factors are additive, then the multilevel multifactor design needs fewer measurements than the classical design in order to give the same precision. Thirdly, optimization can be made with this design and optimum factor levels can be find. The levels correspond to values of 4-8-12-16-20 $\mu \mathrm{g}$ $\mathrm{mL}^{-1}$ for lisinopril and 3-5-7-9-11 $\mu \mathrm{g} \mathrm{mL}^{-1}$ for hydrochlorothiazide. The absorption spectrum of each sample was recorded
$1 \mathrm{~cm}$ cuvettes between $190-400 \mathrm{~nm}$ at $1 \mathrm{~nm}$ intervals aganist a blank of methanol solution. Table-1 shows the composition of the binary mixtures used in calibration set. The validation set was prepared with three different levels of lisinopril and hydrochlorothiazide in the same conditions for calibration solutions. These concentration levels have been selected by considering the amounts of the analyt in the calibration range. Three groups of all samples were prepared and analyzed in three times a day and four consecutive weeks. This procedure allowed us to assess intra- and inter-assay accuracy and precision.

Chromatographic analysis: The determination of the contents of lisinopril and hydrochlorothiazide in tablets was also verified by HPLC using a variable wavelength UV-VIS detector at $213 \mathrm{~nm}$ with a stationary phase mentioned in the Apparatus Section. An isocratic conditions with a mobile phase of acetonitrile and $0.025 \mathrm{M} \mathrm{H}_{3} \mathrm{PO}_{4} / \mathrm{K}_{2} \mathrm{HPO}_{4} \mathrm{pH}$ : 3 buffer solution (20/80) are used.

Pharmaceutical sample preparation: Accurately weighed 20 commercial tablets (Zestoretic Fort ${ }^{\circledR}$ ) were powdered in a mortar and an amount equivalent to one tablet was transferred to a $100 \mathrm{~mL}$ volumetric flask and the drug components were dissolved in $25 \mathrm{~mL}$ of methanol. After $15 \mathrm{~min}$ of mechanical shaking, the flask was completed to volume with the same solvent. The samples were filtered through $0.45 \mu \mathrm{m}$ membranes then further diluted to suit working range for PLS-2, PCR, MLR and HPLC.

\section{RESULTS AND DISCUSSION}

Multivariate calibration methods: The UV spectra of lisinopril $\left(20 \mu \mathrm{g} \mathrm{mL}^{-1}\right)$ and hydrochlorothiazide $\left(12.5 \mu \mathrm{g} \mathrm{mL}^{-1}\right)$ in methanol are shown in Fig. 2. As can be seen in this figure, direct spectrophotometric determination of one compound in presence of second one is not possible due to strong overlapping of their spectra. Therefore, PLS-2, PCR and MLR methods were applied to resolution of mixtures of two components in this study.

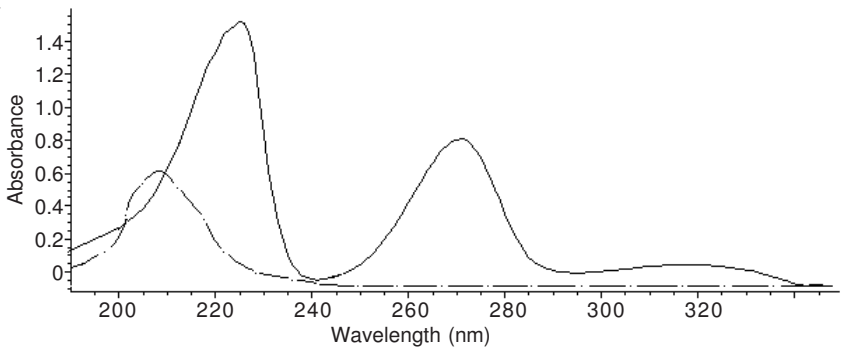

Fig. 2. Absorption spectra of $20 \mu \mathrm{g} \mathrm{mL} \mathrm{m}^{-1}$ lisinopril (-) $12.5 \mu \mathrm{g} \mathrm{mL} \mathrm{mL}^{-1}$ hydrochlorothiazide (---) in methanol

Electronic absorption spectra for the standard samples shown in Table-1 were recorded in the range 190-400 $\mathrm{nm}$ at 211 points and subjected to PLS-2, PCR and MLR analysis. In these methods, calibration was performed using the absorbance

TABLE-1

COMPOSITION OF THE CALIBRATION MATRIX FOR LISINOPRIL (LIS) AND HYDROCHLOROTHIAZIDE $(H C T)\left(\mu \mathrm{g} \mathrm{mL} \mathrm{m}^{-1}\right)$

\begin{tabular}{lcccccccccccccccccccccccccc}
\hline \multicolumn{1}{c}{ Standards } & 1 & 2 & 3 & 4 & 5 & 6 & 7 & 8 & 9 & 10 & 11 & 12 & 13 & 14 & 15 & 16 & 17 & 18 & 19 & 20 & 21 & 22 & 23 & 24 & 25 \\
\hline LIS $\left(\mu \mathrm{g} \mathrm{mL}^{-1}\right)$ & 12 & 12 & 4 & 4 & 20 & 8 & 20 & 12 & 8 & 8 & 16 & 20 & 16 & 12 & 20 & 20 & 4 & 16 & 4 & 12 & 16 & 16 & 8 & 4 & 8 \\
$\mathrm{HCT}\left(\mu \mathrm{g} \mathrm{mL}^{-1}\right)$ & 7 & 3 & 3 & 11 & 5 & 11 & 7 & 5 & 5 & 9 & 11 & 9 & 7 & 11 & 11 & 3 & 9 & 3 & 7 & 9 & 9 & 5 & 3 & 5 & 7 \\
\hline
\end{tabular}


and concentration matrices in order to predict the unknown concentrations of the analytes in their binary mixtures. Usual statistical parameters giving an indication of the quality of fit of all the data are the root-mean square difference (RMSD), relative error of prediction (REP \%) and square of the correlation coefficient $\left(\mathrm{R}^{2}\right)$. The obtained values for the present calibration and optimum number of factors are summarized in Table-2.

Validation set: In order to test the prediction and accuracy performance of the proposed methods intra-day (one day operation under the same conditions) and inter-day (four different days) variations using three different concentration levels were used. The results were summarized in Table- 3 . The values of the root mean square (RMSD) and the relative error of prediction (REP) for each component were included in order to give an indication the average error in the analysis. Good prediction results were obtained.

The RMSD values of intra-day of PLS-2, PCR and MLR for lisinopril are $0.48,0.49$ and 0.50 , for hydrochlorothiazide are $0.23,0.29$ and 0.29 . The REP \% values of PLS-2 and PCR for lisinopril are 4.00, 4.08 and 4.20, for hydrochlorothiazide are $3.30,4.10$ and 4.12 , respectively.
The RMSD values of inter-day of PLS-2, PCR and MLR for lisinopril are $0.45,0.60$ and 0.53 for hydrochlorothiazide are $0.27,0.31$ and 0.31 . The REP \% values of PLS-2 and PCR for lisinopril are 3.76, 5.02 and 4.43 and for hydrochlorothiazide are 3.85, 4.50 and 4.44, respectively. It can be seen that PLS2 gave better results than PCR for all components. It can be assumed that this is generally attributed to the PLS model which accounts for both $\mathrm{x}$ - and $\mathrm{y}$-criteria. This is in contrast with the PCR model where decomposition of the data matrix is based entirely on the $\mathrm{x}$-variable variation.

Tablet analysis: The proposed methods were also applied to the determination of lisinopril and hydrochlorothiazide in tablet samples, as it was described in the experimental part. The assay results obtained by both methods were also statistically compared with classical HPLC method at the $95 \%$ level. The calculated F-values and t-values were found to be less than the critical values at $95 \%$ confidence level (6.39 and 2.31, respectively).

Commercial formulation's results were illustrated in Table-4. The numerical values of all statistical tests indicated that the investigated techniques are suitable for the determination of lisinopril and hydrochlorothiazide in this pharmaceutical dosage form.

TABLE-2

OPTIMUM NUMBER OF FACTORS AND CALIBRATION STATISTICAL PARAMETERS WHEN APPLYING PLS-2, PCR AND MLR

\begin{tabular}{ccc|cc|cc}
\hline Statistical & \multicolumn{2}{c|}{ PLS-2 } & \multicolumn{2}{c|}{ PCR } & \multicolumn{2}{c}{ MLR } \\
\cline { 2 - 7 } parameter* & Lisinopril & Hydrochlorothiazide & Lisinopril & Hydrochlorothiazide & Lisinopril & Hydrochlorothiazide \\
\hline Factors & 3 & 3 & 3 & 3 & - & - \\
RMSD & 0.91 & 0.18 & 1.01 & 0.19 & 0.90 & 0.18 \\
REP\% & 7.6 & 2.58 & 8.4 & 2.7 & 7.50 & 2.53 \\
$R^{2}$ & 0.9750 & 0.9969 & 0.9681 & 0.9954 & 0.9742 & 0.9961 \\
\hline
\end{tabular}

${ }^{*} \mathrm{RMSD}=\left[\frac{1}{\mathrm{~m}} \Sigma_{1}^{\mathrm{m}}\left(\mathrm{c}_{\text {act }}-\mathrm{c}_{\text {pred }}\right)^{2}\right]^{1 / 2} ; \% \mathrm{REP}=\frac{100}{\overline{\mathrm{c}}}\left[\frac{1}{\mathrm{~m}} \Sigma_{1}^{\mathrm{m}}\left(\mathrm{c}_{\text {act }}-\mathrm{c}_{\text {pred }}\right)^{2}\right]^{1 / 2}$ and $\mathrm{R}^{2}=1-\left(\Sigma_{1}^{\mathrm{m}}\left(\mathrm{c}_{\text {act }}-\mathrm{c}_{\text {pred }}\right)^{2}\right) /\left(\Sigma_{1}^{\mathrm{m}}\left(\mathrm{c}_{\text {act }}-\overline{\mathrm{c}}\right)^{2}\right) \overline{\mathrm{c}}$ is the average component

concentration in the $\mathrm{m}$ mixtures.

\begin{tabular}{|c|c|c|c|c|c|c|c|c|c|c|c|c|c|c|c|c|c|c|}
\hline \multicolumn{19}{|c|}{$\begin{array}{l}\text { TABLE-3 } \\
\text { AND ACCURACY OF ASSAY FOR LISINOPRIL AND } \\
\text { ZIDE BY USING PLS-2, PCR and MLR }\end{array}$} \\
\hline & \multicolumn{6}{|c|}{ PLS-2 } & \multicolumn{6}{|c|}{ PCR } & \multicolumn{6}{|c|}{ MLR } \\
\hline & \multicolumn{3}{|c|}{$\begin{array}{l}\text { Lisinopril } \\
\left(\mu \mathrm{g} \mathrm{mL}^{-1}\right)\end{array}$} & \multicolumn{3}{|c|}{$\begin{array}{l}\text { Hydrochlorothiazide } \\
\left(\mu \mathrm{g} \mathrm{mL}^{-1}\right)\end{array}$} & \multicolumn{3}{|c|}{$\begin{array}{l}\text { Lisinopril } \\
\left(\mu \mathrm{g} \mathrm{mL} \mathrm{mL}^{-1}\right)\end{array}$} & \multicolumn{3}{|c|}{$\begin{array}{l}\text { Hydrochlorothiazide } \\
\left(\mu \mathrm{g} \mathrm{mL}^{-1}\right)\end{array}$} & \multicolumn{3}{|c|}{$\begin{array}{l}\text { Lisinopril } \\
\left(\mu \mathrm{g} \mathrm{mL}^{-1}\right)\end{array}$} & \multicolumn{3}{|c|}{$\begin{array}{l}\text { Hydrochlorothiazide } \\
\left(\mu \mathrm{g} \mathrm{mL}^{-1}\right)\end{array}$} \\
\hline & 20.00 & 12.00 & 4.00 & 11.00 & 7.00 & 3.00 & 20.00 & 12.00 & 4.00 & 11.00 & 7.00 & 3.00 & 20.00 & 12.00 & 4.00 & 11.00 & 7.00 & 3.00 \\
\hline \multirow[t]{2}{*}{ Intra-assay } & 19.60 & 12.07 & 4.08 & 11.26 & 7.21 & 3.21 & 19.57 & 12.53 & 4.24 & 11.39 & 7.36 & 3.20 & 19.43 & 12.43 & 4.15 & 11.44 & 7.35 & 3.22 \\
\hline & 19.30 & 12.60 & 4.27 & 11.18 & 7.13 & 3.11 & 19.16 & 12.53 & 4.30 & 11.16 & 7.35 & 3.21 & 19.13 & 12.40 & 4.12 & 11.29 & 7.20 & 3.25 \\
\hline RMSD & & 0.48 & & & 0.23 & & & 0.49 & & & 0.29 & & & 0.50 & & & 0.29 & \\
\hline REP (\%) & & 4.00 & & & 3.30 & & & 4.08 & & & 4.10 & & & 4.20 & & & 4.12 & \\
\hline Recovery (\%) & & 100.16 & & & 102.63 & & & 100.82 & & & 103.82 & & & 99.61 & & & 103.79 & \\
\hline \multirow[t]{4}{*}{ Inter-assay } & 19.44 & 12.49 & 4.25 & 11.26 & 7.26 & 3.19 & 19.40 & 12.97 & 4.21 & 11.27 & 7.27 & 3.15 & 19.36 & 12.46 & 4.10 & 11.10 & 6.87 & 3.18 \\
\hline & 19.43 & 12.60 & 4.23 & 11.04 & 6.90 & 2.98 & 19.29 & 12.58 & 4.13 & 11.04 & 6.67 & 3.24 & 19.34 & 12.55 & 4.11 & 11.80 & 7.23 & 2.98 \\
\hline & 18.99 & 11.72 & 4.10 & 11.79 & 7.08 & 3.15 & 18.68 & 11.70 & 4.38 & 11.73 & 7.51 & 2.97 & 18.80 & 11.67 & 4.29 & 11.34 & 7.25 & 3.29 \\
\hline & 20.22 & 12.43 & 4.38 & 11.24 & 6.97 & 3.13 & 20.08 & 12.41 & 4.29 & 11.29 & 7.20 & 3.25 & 20.12 & 12.23 & 4.21 & 11.29 & 7.15 & 3.22 \\
\hline RMSD & & 0.45 & & & 0.27 & & & 0.60 & & & 0.31 & & & 0.53 & & & 0.31 & \\
\hline Recovery (\%) & & 100.19 & & & 102.37 & & & 100.08 & & & 103.44 & & & 99.33 & & & 103.21 & \\
\hline
\end{tabular}

TABLE-4

COMPARISON OF RESULTS IN FOUR METHOD ANALYSIS OF COMMERCIAL FORMULATION (Zestoretic Fort ${ }^{\circledR}$ )

\begin{tabular}{ccc|cc|ccc|cc}
\hline \multirow{2}{*}{$\mathrm{n} 1=\mathrm{n} 2=5$} & \multicolumn{2}{c|}{ HPLC } & \multicolumn{2}{c|}{ PLS-2 } & \multicolumn{2}{c|}{ PCR } & \multicolumn{2}{c}{ MLR } \\
\cline { 2 - 10 } & LIS & HCT & LIS & HCT & LIS & HCT & LIS & HCT \\
Mean \pm SD & $19.73 \pm 0.26$ & $12.24 \pm 0.19$ & $19.67 \pm 0.43$ & $12.50 \pm 0.24$ & $19.38 \pm 0.45$ & $12.48 \pm 0.24$ & $19.43 \pm 0.47$ & $12.51 \pm 0.36$ \\
Recovery\% & 98.65 & 97.92 & 98.40 & 100.00 & 96.90 & 99.84 & 97.15 & 100.08 \\
$\mathrm{t}$ test of significance & & & 0.26 & 1.42 & 1.51 & 1.77 & 1.25 & 1.50 \\
F test of significance & & & 2.73 & 1.60 & 2.86 & 1.66 & 3.11 & 3.68 \\
\hline
\end{tabular}

$\mathrm{t}_{8}^{0.05}=2.31 \mathrm{~F}_{4,4}{ }^{0.05}=6.39 ;$ LIS $=$ Lisinopril; HCT $=$ Hydrochlorothiazide 


\section{Conclusion}

PLS-2, PCR and MLR methods were applied for the simultaneous determination of lisinopril and hydrochlorothiazide in tablet preparation. We observed that the assay results of the multivariate calibration methods obtained by us are comparable with the spectrophotometric methods ${ }^{1,2}$, chromatographic methods ${ }^{3,4}$ and electrophoresis ${ }^{5}$ for the determination of lisinopril and hydrochlorothiazide in the same mixture. The multivariate calibration methods are more rapid, reliable and economic than the other methods. Because these methods do not require expensive equipment and materials such as columns and solvents as used in HPLC, sophisticated instrument and buffer solutions as in electrophoresis, a derivation of spectrum and selection critical wavelengths as used in derivative spectrophotometry and a derivation and a division of spectra used in ratio spectra derivative spectrophotometry described in above literature. The results also showed that the lowest relative standard deviations were obtained for lisinopril and hydrochlorothiazide by using PLS-2 in comparison with the other chemometric methods in the literature ${ }^{4}$.

In conclusion, the proposed methods allow easy and fast determination of lisinopril and hydrochlorothiazide in tablet samples and can be used for routine drug analysis.

\section{REFERENCES}

1. $\quad$ N. Erk, Spectrosc. Lett., 31, 633 (1998)

2. N. Erk and M. Kartal, Anal. Lett., 32, 1131 (1999).
3. D. Ivanovic, M. Medenica, B. Jancic, N. Kne•evic, A. Malenovic and J. Milic, Acta Chromatogr., 18, 143 (2007).

4. A. El-Gindy, A. Ashour, L. Abdel-Fattah and M.M. Shabana, J. Pharm. Biomed. Anal., 25, 923 (2001).

5. S. Hillaert, K. De Grauwe and W. Van den Bossche, J. Chromatogr. A, 924, 439 (2001).

6. H. Khajehsharifi, Z. Eskandari and A. Asadipour, Drug Test. Anal., 2, $162(2010)$

7. A.C. Mot, F. Soponar, A. Medvedovici and C. Sarbu, Anal. Lett., 43, 804 (2010).

8. A. Samadi-Maybodi and S.K.H. Nejad-Darzi, Spectrochim. Acta A, 75, 1270 (2010).

9. M. Chamsaz, M.H. Arbabzavar, T. Heidari, A. Hajinia and T. Salehi, Asian J. Chem., 22, 4717 (2010).

10. R.M. Maggio, P.M. Castellano and T.S. Kaufman, Anal. Bioanal. Chem., 391, 2949 (2008).

11. E. Dinç, A. Bilgili and B. Hanedan, Pharmazie, 62, 179 (2007).

12. E. Dinç, M. Kanbur and D. Baleanu, Rev. Chim., 58, 195 (2007).

13. A.P. do Nascimento, M.G. Trevisan, E.R.M. Kedor-Hackmann and R.J. Poppi, Anal. Lett., 40, 975 (2007).

14. J. Ghasemi, A. Niazi and S. Ghobadi, J. Chin. Chem. Soc., 52, 1049 (2005).

15. E. Dinç, Anal. Lett., 35, 1021 (2002).

16. N. A.El-Ragehy, S.S. Abbas and S. Z. El-Khateeb, Anal. Chim. Acta, 461, 155 (2002).

17. M.C.F. Ferraro, P.M. Castellano and T.S. Kaufman, J. Pharm. Biomed. Anal., 30, 1121 (2002).

18. Ö.A. Dönmez, A. Bozdogan, G. Kunt and Y. Div, J. Anal. Chem., 65, 30 (2010).

19. Ö.A. Dönmez, A. Bozdogan, G. Kunt and Y. Div, Chem. Anal., 52, 135 (2007).

20. Ö.A. Dönmez, A. Bozdogan and G. Kunt, Rev. Anal. Chem., 26, 209 (2007).

21. R.G. Brereton, Analyst, 122, 1521 (1997). 